\title{
The mathematical modeling of the lactation curve for dairy traits of the donkey (Equus asinus)
}

\author{
S. Bordonaro, ${ }^{\star}$ C. Dimauro, $†$ A. Criscione, ${ }^{\star}$ D. Marletta, ${ }^{\star}$ and N. P. P. Macciotta ${ }^{1}$ \\ *Dipartimento di Scienze delle Produzioni Agrarie ed Alimentari, Sezione di Produzioni Animali, via Valdisavoia, 5, 95123 Catania, Italy \\ †Dipartimento di Agraria, Sezione Scienze Zootecniche, Università di Sassari, Viale Italia 39, 07100, Sassari, Italy
}

\begin{abstract}
In recent years, an increase in the number of donkeys farmed in Italy as a consequence of the growing demand for donkey milk for direct consumption has been observed. Some research has been carried out on jenny milk composition and on its nutritional properties, whereas milk production features are scarcely described for this species. In this work, the lactation curve shape of donkeys for milk yield and composition was investigated. A total of 453 test-day records for milk yield, fat and protein percentage, and somatic cell count of 62 lactations measured on 46 multiparous jennies of the Ragusano breed were considered. Effects of herd, age, and foaling season were assessed by using a mixed model analysis. Average and individual lactation curves were fitted using the Wood incomplete gamma function, the Cappio-Borlino modified gamma, and a third-order Legendre orthogonal polynomial model. Donkeys foaling between 6- and 10-yr-old had the highest test-day milk yield (about $1.85 \mathrm{~kg} / \mathrm{d}$ ). Donkeys foaling in winter and autumn had a higher daily milk yield compared with those foaling in summer and spring. Less defined results were obtained for composition traits. The general pattern of the donkey lactation curve is similar to the standard shape reported for the main dairy ruminant species, with a peak yield occurring at about $5 \mathrm{wk}$ from parturition. Younger jennies tended to have lower production peaks and higher lactation persistency. Similarly to what is reported for dairy cattle, a large variability in individual patterns has been observed. No differences in goodness of fit have been observed between the models in the case of average lactation curves, whereas orthogonal polynomials were more efficient in fitting individual patterns.
\end{abstract}

Key words: donkey milk, lactation curve, mathematical model

Received September 20, 2012.

Accepted March 3, 2013.

${ }^{1}$ Corresponding author: macciott@uniss.it

\section{INTRODUCTION}

The population of donkeys farmed in Italy experienced a progressive decrease between 1960 and 2000, from about 500,000 to 23,000 individuals (FAO STAT, 2012). Such a negative trend, common to other European countries, can be ascribed, essentially, to the diffusion of mechanization in agriculture and to the subsequent loss of the traditional role of this species as an animal of draft and burden (Bordonaro et al., 2012). In Italy, donkey farming is currently based on local breeds. At present, 8 autochthonous populations are farmed (Colli et al., 2013); they have been all classified by FAOSTAT (2012) as critically endangered. The most common breeds are Ragusano $(1,895)$, Amiata $(1,599)$, and Sardo $(1,318)$; other breeds have fewer than 1,000 animals each (AIA, 2012).

However, in the last 10 years, the number of asses has increased to about 53,500 (AIA, 2012). A reason for this is an increasing demand for donkey milk related to its composition, which is more similar to human milk than other dairy species (Salimei and Fantuz, 2012). This feature makes donkey milk particularly suitable for fulfilling the nutritional requirements of babies that cannot be breast-fed and for consumers suffering from cow milk protein allergies (Carroccio et al., 2000; Monti et al., 2007; Tesse et al., 2009). In the last few years, research has mainly been conducted on donkey milk nutritional properties and chemical composition (Bertino et al., 2010; Gastaldi et al., 2010; Tidona et al., 2011).

In Italy, the number of donkey farms, most of which are specialized for milk production, has also increased and could be estimated to be around 100 to 200. The most common breeds in specialized farms are Ragusano and Martina Franca. The traditional farming system is semiextensive. Animals are usually fed hay and allowed to graze when pasture is available. Most of farms are small, with less than 50 animals. According to Italian law, fresh donkey milk can be sold at the farm; current market prices range between 10 and 20 euros per liter.

Studies on the general features of production and the effects of main environmental sources of variation 
are rather limited. Such studies are essential to develop suitable strategies for the improvement of the donkey milk industry, however. For example, foaling season, heat stress, and feeding have been found to considerably affect productive performances (Giosuè et al., 2008). Recent studies carried out on Italian donkey breeds reported an effect of milking regimen on milk yield and composition (Alabiso et al., 2009; D'Alessandro and Martemucci, 2012)

The mathematical description of the lactation curve represents an important tool for the assessment of production features of a dairy species and for the evaluation of effects of nongenetic sources of variation (Macciotta et al., 2011). The most popular model of the lactation curve, the Wood incomplete gamma function, has also been used to fit individual curves of lactating jennies (D'Alessandro and Martemucci, 2012) and mares (Santos and Silvestre, 2008). It is worth mentioning that fitting mathematical functions to the evolution of milk yield over time allows the separation of the lactation stage effect from other environmental factors only when they average out over lactation (Jamrozik and Schaeffer, 1997). This issue is addressed by the use of mixed linear models that include the fixed effect of DIM classes, whose least squares solutions allow the generation of lactation curves corrected for other sources of variation that may have different effects at specific lactation stages (Stanton et al., 1992).

The aim of the current paper is to describe the lactation curve shape of donkeys for milk yield and composition and its main characteristics. Moreover, the effect of some environmental factors on average lactation patterns is investigated herein. With this aim, average and individual curves were analyzed by using either linear mixed models or continuous functions of time.

\section{MATERIALS AND METHODS}

\section{Data}

Data were test-day records of 62 lactations recorded on 46 jennies of different ages (from 3-17-yr-old) at foaling of Ragusano breed, autochtonous of Sicily. Animals were farmed in 2 specialized herds (>100 animals) in eastern Sicily, characterized by a different feeding management. In the first herd, located at the foot of the Etna volcano (550 $\mathrm{m}$ above sea level), animals were fed a TMR containing oats, barley, grain by-products, straw, and minerals. In the second herd, located in a hilly area of the province of Ragusa (515 $\mathrm{m}$ above sea level), the diet consisted of wheat straw plus a commercial concentrate $(2 \mathrm{~kg} / \mathrm{d})$ and grazing on a seasonal pasture (October-May). In the first and in the second herd there were 16 and 30 animals, respectively.
Individual milk yields were recorded once a month, according to the official A4 protocol of the Italian Breeders Association, as the sum of the morning and evening milkings in the period from June 2007 to July 2009. Donkeys were machine-milked twice a day (at 1100 and $1600 \mathrm{~h}$ ) using a wheeled trolley type with a sheep cluster. The first test occurred between 20 and 40 d after parturition (18 lactations had the first test recorded before 35 DIM). Foals were separated from their dams at $0600 \mathrm{~h}$ and rejoined after the second milking. Data recording was performed for the whole lactation. Individual milk samples were collected at each milking and stored at $4^{\circ} \mathrm{C}$. Protein and fat contents and SCC were determined by using a Milkoscan Foss 120 (Foss Electric A/S, Hillerød, Denmark), calibrated with specific standards for donkey milk. Somatic cell score was calculated as $\log _{2}[(\mathrm{SCC} \times 1,000) / 100]+3($ Ali and Shook, 1980). A total of 453 test-day records for milk yield and fat and protein percentages measured on 62 lactations were available for the statistical analysis (16 jennies had 2 consecutive lactations recorded). Test day records were grouped into 9 DIM intervals, the first of $60 \mathrm{~d}$, the other of $30 \mathrm{~d}$.

\section{Models}

Both average and individual lactation curves were fitted. Average patterns, corrected for the effects of some environmental factors were estimated using the following mixed linear model:

$$
\begin{gathered}
y_{i j k l m n o}=b_{0}+b_{1} \mathrm{TD}_{i}+\mathrm{HERD}_{j}+\mathrm{SEA}_{k} \\
+\mathrm{AGE}_{l}+\mathrm{DIM}_{m}+L_{n}+e_{i j k l m n o}
\end{gathered}
$$

where $y=$ the $o$ th test for milk yield, fat or protein percentage, and somatic cell score; $b_{0}=$ the overall mean; $b \mathrm{TD}=$ the fixed covariable represented by the $i$ th test day; HERD = fixed effect of the $j$ th herd (2 levels); $\mathrm{SEA}=$ fixed effect of the $k$ th season of parturition $(4$ levels); $\mathrm{AGE}=$ fixed effect of the $l$ th age at parturition class in years $(5$ levels: $<5,5,6,7-10,>10)$; DIM $=$ fixed effect of the $m$ th DIM interval (9 intervals, the first of $60 \mathrm{~d}$, the others of $30 \mathrm{~d}$ ); $L=$ random effect of the $n$th donkey (46 levels); and $e=$ random residual.

The covariable of the date of the test was included to account for environmental variation peculiar to each sampling day. The DIM effect allowed for the estimation of average lactation curves of jennies of different age class adjusted for the other factors included in model 1 (Stanton et al., 1992). This option was preferred to the use of one or more covariables because, in a comparison with different functions of the lactation curve, fixed effect classes had the best fit (Druet et al., 
Table 1. Raw means and standard deviation for days, milk yield (MY), fat (FP) and protein (PP) percentages, and SCC for different lactation intervals

\begin{tabular}{|c|c|c|c|c|c|c|}
\hline $\begin{array}{l}\text { DIM } \\
\text { interval }\end{array}$ & $\mathrm{n}^{1}$ & Day & \multicolumn{4}{|c|}{ Trait } \\
\hline 2 & 61 & $73 \pm 8$ & $2.15 \pm 0.64$ & $0.12 \pm 0.05$ & $1.55 \pm 0.41$ & $10.34 \pm 12.78$ \\
\hline 3 & 63 & $104 \pm 8$ & $2.07 \pm 0.62$ & $0.15 \pm 0.17$ & $1.59 \pm 0.14$ & $9.37 \pm 11.72$ \\
\hline 4 & 58 & $134 \pm 7$ & $1.87 \pm 0.54$ & $0.17 \pm 0.21$ & $1.58 \pm 0.13$ & $7.67 \pm 6.25$ \\
\hline 7 & 37 & $223 \pm 8$ & $1.53 \pm 0.50$ & $0.13 \pm 0.12$ & $1.50 \pm 0.11$ & $11.00 \pm 15.25$ \\
\hline 8 & 27 & $253 \pm 9$ & $1.41 \pm 0.52$ & $0.11 \pm 0.05$ & $1.45 \pm 0.12$ & $13.08 \pm 19.33$ \\
\hline 9 & 33 & $297 \pm 18$ & $1.25 \pm 0.47$ & $0.13 \pm 0.13$ & $1.43 \pm 0.13$ & $42.35 \pm 65.67$ \\
\hline Overall & 453 & & $1.71 \pm 0.66$ & $0.15 \pm 0.16$ & $1.53 \pm 0.16$ & $13.05 \pm 26.01$ \\
\hline
\end{tabular}

${ }^{1}$ Number of observations.

2003). The $L$ random factor takes into account the variability associated with each individual jenny (Stanton et al., 1992). Thus, the related variance component $\sigma_{L}^{2}$ represents the between-animal variability, whereas the residual variance $\sigma_{e}^{2}$ represents the within-animal variability. The average correlation between tests within lactation, or repeatability, was calculated as the ratio $\sigma_{L}^{2} /\left(\sigma_{L}^{2}+\sigma_{e}^{2}\right)$ (Littell et al., 1998).

Average lactation curves of jennies of different herd, age and season of parturition were estimated by running model 1 with the DIM effect nested within the specific factor [i.e., DIM(HERD), DIM(AGE), $\operatorname{DIM}(\mathrm{SEA})]$. Least squares means of average curves for milk yield, fat, and protein percentages, somatic cell core were then fitted with the following mathematical models of the lactation curve (in which $y$ represents the milk yield, fat or protein percentage, and SCC at day $t$ from parturition, and $a, b, c, \alpha_{0}, \alpha_{1}, \alpha_{2}$, and $\alpha_{3}$ are parameters to be estimated):

The incomplete gamma function of Wood (WD; Wood, 1967) is represented as

$$
y_{t}=a t^{b} e^{-c t} .
$$

Although its limits are well known, it is still the most widely used model of the lactation curve for many dairy and nondairy species (Landete Castillejos and Gallego, 2000; Dijkstra et al., 2010). It has been used to fit lactation curves of donkeys (D'Alessandro and Martemucci, 2012) and mares (Santos and Silvestre, 2008). The WD model has been also used to fit milk composition traits in cattle (Silvestre et al., 2009; Strucken et al., 2011). The second model was a modification of the Wood function proposed by Cappio-Borlino et al. (1995) (CB):

$$
y_{t}=a t^{b \exp (c t)} .
$$

Considering that the first test record occurred, on average, in the second month of lactation (Table 1), the CB function was chosen for its superior efficiency in describing a rapid increase in the first phase of lactation (Franci et al., 1999) compared with the original WD model. The 2 models were fitted using a nonlinear regression procedure (SAS Institute, 2008) and the Marquardt compromise as estimation method. Prior parameter values were estimated by running the models on the whole data set.

The last function was a third-order Legendre orthogonal polynomial (LEG3):

$$
y_{t}=\alpha_{0} \times P_{0}+\alpha_{1} \times P_{1}+\alpha_{2} \times P_{2}+\alpha_{3} \times P_{3} .
$$

The LEG3 function was selected to compare differences in model flexibility due to the number of parameters and the degree of correlation among them. Due to its properties, this model is expected to yield good performances when fitting irregular patterns such as individual curves or component traits. The model was solved using a linear regression procedure. Time was standardized $(w)$ as

$$
w=\frac{2\left(t-t_{\min }\right)}{\left(t_{\max }-t_{\min }\right)}-1
$$

where $t_{\min }$ and $t_{\max }$ are the earliest and latest DIM represented in the data set, respectively. Functions of time $\left(P_{j}\right)$ of LEG3 were then calculated using values published by Schaeffer (2004). The main traits that characterize the lactation curve, that is, time at peak occurrence $\left(t_{m}\right)$, peak yield $\left(y_{m}\right)$, and persistency, were calculated for WD model using parameter combinations based on France and Thornley (1984)

$$
t_{m}=\frac{b}{c}
$$




$$
y_{m}=\frac{a}{\left(\frac{c}{b}\right)^{b} e^{b}}, \text { and }
$$

persistency $=-(b+1) \ln c$,

where $a, b$, and $c$ are parameters of the Wood model and $e$ is the base of natural logarithms

For CB and LEG3, $y_{m}$ and $t_{m}$ were empirically obtained by finding the largest value among daily yields predicted by the model for the whole lactation interval. Total milk yield at d 300 was obtained for all models by summing predicted daily yields. Model fitting performances were compared by using $\mathrm{R}^{2}$. The existence of serial autocorrelation between residuals was assessed using the Durbin Watson (DW) statistics.

The 3 models described above were also fitted to individual lactation data. Goodness of fit of the different models was assessed by examining the distribution of the coefficient of determination across 5 classes $(1=$ $<0.20 ; 2=0.20-0.40 ; 3=0.40-0.60 ; 4=0.60-0.80 ; 5$ $=>0.80)$.

\section{RESULTS AND DISCUSSION}

\section{Milk Yield and Composition}

Average values for milk yield and composition across the whole lactation and for each DIM interval are re- ported in Table 1. Values for fat and protein content are in the range reported on previous studies on Italian and Chinese donkeys (Salimei et al., 2004; Guo et al., 2007). A relevant variability for SCS and fat percentage, both positively skewed (CV of 199 and 106\%, respectively), can be observed. This behavior of fat content in donkey milk was reported also by Giosuè et al. (2008).

\section{Mixed Model Analysis}

Mixed model analysis revealed a statistically significant effect of lactation stage, age of the donkey and season of parturition $(P<0.01)$ on milk yield (Table 2$)$. In particular, jennies 6- to 10-yr-old at parturition had a higher average milk yield compared with the youngest class $(P<0.001)$. Donkeys foaling in autumn had a higher daily milk yield compared with those foaling in summer and spring. Higher milk yields for winter foalings in Ragusano jennies were reported also by Giosuè et al. (2008). A recent report on a local donkey population in southern Italy found an effect of foaling season on donkey milk yield, with the largest values in summer compared with spring (Cosentino et al., 2012). No significant effect of the herd on milk yield was observed. Repeatability of milk yield was 0.56 . This value is similar to those currently reported for dairy cattle (Stanton et al., 1992; Macciotta et al., 2011).

Fat percentage was not affected by any of the factors considered in the analysis (Table 2). This result could

Table 2. Least squares means (SE in parentheses) of dairy traits for the different levels of fixed factors considered in model 1

\begin{tabular}{|c|c|c|c|c|}
\hline Effect & Milk yield (kg/d) & Fat $(\%)$ & Protein (\%) & SCS \\
\hline \multicolumn{5}{|l|}{ Herd } \\
\hline Leggio & $1.73(0.09)$ & $0.15(0.02)$ & $1.56^{\mathrm{A}}(0.02)$ & $8.96^{\mathrm{A}}(0.16)$ \\
\hline Torrisi & $1.54(0.09)$ & $0.15(0.02)$ & $1.50^{\mathrm{B}}(0.01)$ & $9.51^{\mathrm{B}}(0.14)$ \\
\hline \multicolumn{5}{|l|}{ Season } \\
\hline Summer & $1.41^{\mathrm{a}}(0.09)$ & $0.12(0.02)$ & $1.50^{\mathrm{a}}(0.02)$ & $8.95(0.16)$ \\
\hline Autumn & $1.74^{\mathrm{b}}(0.10)$ & $0.15(0.02)$ & $1.55^{\mathrm{a}}(0.02)$ & $9.17(0.19)$ \\
\hline Winter & $1.81^{\mathrm{ab}}(0.15)$ & $0.22(0.03)$ & $1.58^{\mathrm{ab}}(0.03)$ & $9.38(0.26)$ \\
\hline Spring & $1.56^{\mathrm{a}}(0.11)$ & $0.11(0.03)$ & $1.49^{\mathrm{ac}}(0.02)$ & $9.46(0.21)$ \\
\hline \multicolumn{5}{|l|}{ Age class } \\
\hline$<5$ & $1.29^{\mathrm{A}}(0.15)$ & $0.11(0.03)$ & $1.55^{\mathrm{a}}(0.03)$ & $9.02(0.27)$ \\
\hline 5 & $1.50^{\mathrm{AB}}(0.16)$ & $0.16(0.04)$ & $1.53^{\mathrm{a}}(0.03)$ & $9.37(0.29)$ \\
\hline 6 & $1.83^{\mathrm{AB}}(0.16)$ & $0.12(0.03)$ & $1.46^{\mathrm{ab}}(0.03)$ & $9.16(0.28)$ \\
\hline $6-10$ & $1.88^{\mathrm{B}}(0.09)$ & $0.16(0.02)$ & $1.54^{\mathrm{a}}(0.02)$ & $9.25(0.16)$ \\
\hline$>10$ & $1.65^{\mathrm{AB}}(0.09)$ & $0.21(0.02)$ & $1.57^{\mathrm{ac}}(0.02)$ & $9.40(0.18)$ \\
\hline \multicolumn{5}{|l|}{ DIM } \\
\hline 1 & $2.16^{\mathrm{A}}(0.09)$ & $0.15(0.03)$ & $1.63^{\mathrm{A}}(0.02)$ & $9.17^{\mathrm{AB}, \mathrm{a}}(0.23)$ \\
\hline 2 & $2.08^{\mathrm{AB}}(0.08)$ & $0.15(0.02)$ & $1.59^{\mathrm{AB}}(0.02)$ & $8.98^{\mathrm{A}}(0.20)$ \\
\hline 3 & $1.85^{\mathrm{BC}}(0.08)$ & $0.17(0.02)$ & $1.58^{\mathrm{AB}}(0.02)$ & $8.91^{\mathrm{A}}(0.19)$ \\
\hline 4 & $1.75^{\mathrm{C}}(0.08)$ & $0.15(0.03)$ & $1.55^{\mathrm{ABC}}(0.02)$ & $8.94^{\mathrm{A}}(0.23)$ \\
\hline 5 & $1.57^{\mathrm{C}}(0.08)$ & $0.14(0.02)$ & $1.53^{\mathrm{ABC}}(0.02)^{\prime}$ & $9.17^{\mathrm{AB}, \mathrm{a}}(0.20)$ \\
\hline 6 & $1.54^{\mathrm{C}}(0.08)$ & $0.16(0.03)$ & $1.5^{\mathrm{BC}}(0.03)$ & $9.23^{\mathrm{AB}, \mathrm{a}}(0.23)$ \\
\hline 7 & $1.45^{\mathrm{C}}(0.10)$ & $0.12(0.03)$ & $1.49^{\mathrm{BC}}(0.03)$ & $9.03^{\mathrm{AB}, \mathrm{a}}(0.27)$ \\
\hline 8 & $1.24^{\mathrm{CD}}(0.11)$ & $0.11(0.04)$ & $1.45^{\mathrm{BC}}(0.03)$ & $9.03^{\mathrm{AB}, \mathrm{a}}(0.32)$ \\
\hline 9 & $1.07^{\mathrm{D}}(0.10)$ & $0.19(0.03)$ & $1.43^{\mathrm{C}}(0.03)$ & $10.38^{\mathrm{B}, \mathrm{b}}(0.30)$ \\
\hline
\end{tabular}

\footnotetext{
${ }_{\mathrm{A}-\mathrm{D}}$ Means within columns with different superscripts differ (Bonferroni adjusted significance level $P<0.01$ ).

${ }^{\mathrm{a}-\mathrm{c}}$ Means within columns with different superscripts differ (Bonferroni adjusted significance level $P<0.05$ ).
} 
be ascribed to the great variability of the trait and to the positive skewness of raw mean values (Table 1 ). The repeatability was 0.14 . Protein percentage was affected by herd $(P<0.01)$, age, and foaling season $(P$ $<0.05)$. No definite pattern can be observed across age classes. Highest protein contents were found for winter and autumn foalings. The average correlation within lactation for this trait was 0.10. Somatic cell score was affected by herd $(P<0.01)$ and stage of lactation $(P$ $<0.05)$. The herd with the lowest average SCS tended also to have higher milk yield (not statistically significant) and protein percentage. The repeatability of the trait was 0.08 .

\section{Average Lactation Curve Modeling}

Both the WD and CB models were able to estimate a standard shape of the average lactation curve for milk yield (Figure 1a), whereas an atypical shape was estimated by the LEG3 polynomials. This result should be ascribed basically to the mathematical structure of the models: WD and CB have been specifically conceived to fit the standard shape of the lactation curve, whereas LEG3 is a more general function. Peak production occurred at about 5 wk from parturition according to the WD model, and a couple of weeks later for the $\mathrm{CB}$ function (Table 3 and Figure 1a). In both cases, peak occurrence was earlier compared with previous reports on other Italian donkey breeds (Salimei et al., 2004; D'Alessandro and Martemucci, 2012), whereas it was closer to the value reported for the Lusitano Mare (San- tos and Silvestre, 2008). It should be remembered that a relevant part of lactations had the first test recorded in the second month of lactation (i.e., after the lactation peak occurrence), and this may have affected the results. Also peak yield, similar between $\mathrm{WD}$ and $\mathrm{CB}$, was larger than previous reports on Italian breeds. Total milk yield for a lactation length of $300 \mathrm{~d}$ is similar to values reported by Giosuè et al. (2008) for the Ragusano donkey. The magnitude parameter values for $\mathrm{WD}$, especially $a$ and $c$, were smaller than results found in horses and closer to values reported for small ruminants (Macciotta et al., 2008). Goodness of fit was similar between all the 3 models as far as $\mathrm{R}^{2}$ is concerned. The DW statistics indicated the existence of strong positive autocorrelation between residuals for the WD function and, to a lesser extent, for the CB model.

Fat percentage showed the classical pattern, opposite that of milk yield (Figure 1b). The WD and CB models gave basically the same poor fit; LEG3, due to its greater flexibility, was able to fit all the waves occurring along the lactation. As a consequence, fitting performances were extremely poor for the first 2 models and rather good for the polynomial function $\left(\mathrm{R}^{2}>0.80\right)$. This is an expected result, considering that these 2 models are more appropriate for modeling the standard pattern for milk yield. The 3 models basically agreed on the minimum value of fat content (about $0.13 \%$ ), whereas its occurrence was similar for WD and $\mathrm{CB}$ and earlier for LEG3. The analysis of autocorrelation between residuals basically confirmed what was already observed for milk yield.

Table 3. Lactation curve parameters and characteristics for the average lactation curves of different traits estimated with Wood (WD), CappioBorlino (CB), and third-order Legendre polynomials (LEG3) models ${ }^{1}$

\begin{tabular}{|c|c|c|c|c|c|c|c|c|c|c|c|c|}
\hline Item $^{2}$ & $a$ & $b$ & $c$ & $t_{m}{ }^{3}$ & $y_{m}{ }^{4}$ & $y_{\text {tot }}^{5}$ & $\mathrm{R}^{2}$ & $\mathrm{DW}^{6}$ & $\alpha_{0}$ & $\alpha_{1}$ & $\alpha_{2}$ & $\alpha_{3}$ \\
\hline MY & 1.47 & 0.15 & -0.003 & 36 & 2.18 & 494 & 0.98 & 0.35 & & & & \\
\hline SCS & 13.55 & -0.12 & 0.001 & 94 & 8.86 & 9.34 & 0.68 & 0.32 & & & & \\
\hline \multicolumn{13}{|l|}{$\mathrm{CB}$} \\
\hline MY & 0.69 & 0.39 & -0.005 & 48 & 2.21 & 487 & 0.96 & 1.18 & & & & \\
\hline SCS & 9.09 & 0.00 & 0.049 & NA & NA & 9.27 & 0.93 & 2.03 & & & & \\
\hline \multicolumn{13}{|l|}{ LEG3 } \\
\hline MY & & & & NA & NA & 499 & 0.98 & 2.41 & 1.704 & -0.532 & -0.029 & -0.025 \\
\hline $\mathrm{FP}$ & & & & 203 & 0.12 & 0.15 & 0.83 & 2.42 & 0.143 & 0.006 & 0.001 & 0.364 \\
\hline PP & & & & 19 & 1.61 & 1.54 & 0.99 & 3.45 & 1.542 & -0.077 & -0.004 & 0.009 \\
\hline SCS & & & & 161 & 9.09 & 9.26 & 0.78 & 1.79 & 9.203 & 0.179 & 0.303 & 0.150 \\
\hline
\end{tabular}

${ }^{1} a, b, c, \alpha_{0}, \alpha_{1}, \alpha_{2}$, and $\alpha_{3}=$ parameters of the lactation curve functions.

${ }^{2} \mathrm{MY}=$ milk yield; $\mathrm{FP}=$ fat percentage; $\mathrm{PP}=$ protein percentage.

${ }^{3} t_{m}=$ time (days) at which lactation peak is reached.

${ }^{4} y_{m}=$ yield or content at lactation peak.

${ }^{5} y_{\text {tot }}=$ for MY, cumulated lactation yield in $300 \mathrm{~d}$ of lactation; for FP, PP, and SCS, average daily content along a lactation of $300 \mathrm{~d}$.

${ }^{6}$ Durbin Watson statistics. 
Table 4. Lactation curve parameters, time at peak occurrence $\left(t_{m}\right)$, peak yield $\left(y_{m}\right)$, persistency (Pers), total milk yield for a standardized lactation length of $300 \mathrm{~d}\left(y_{\text {tot }}\right)$, and goodness of fit statistics for the Wood model fitted to average lactation curves of different age at foaling, herds, and foaling season, respectively ${ }^{1}$

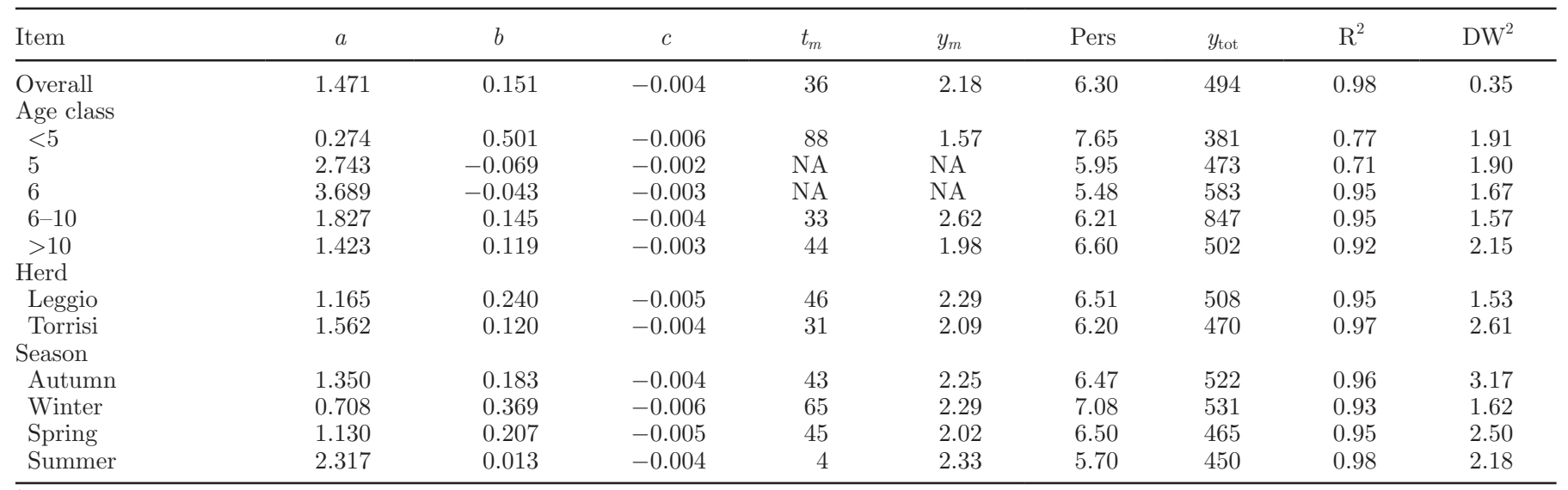

${ }^{1} a, b, c=$ parameters of the Wood model.

${ }^{2}$ Durbin Watson statistics.
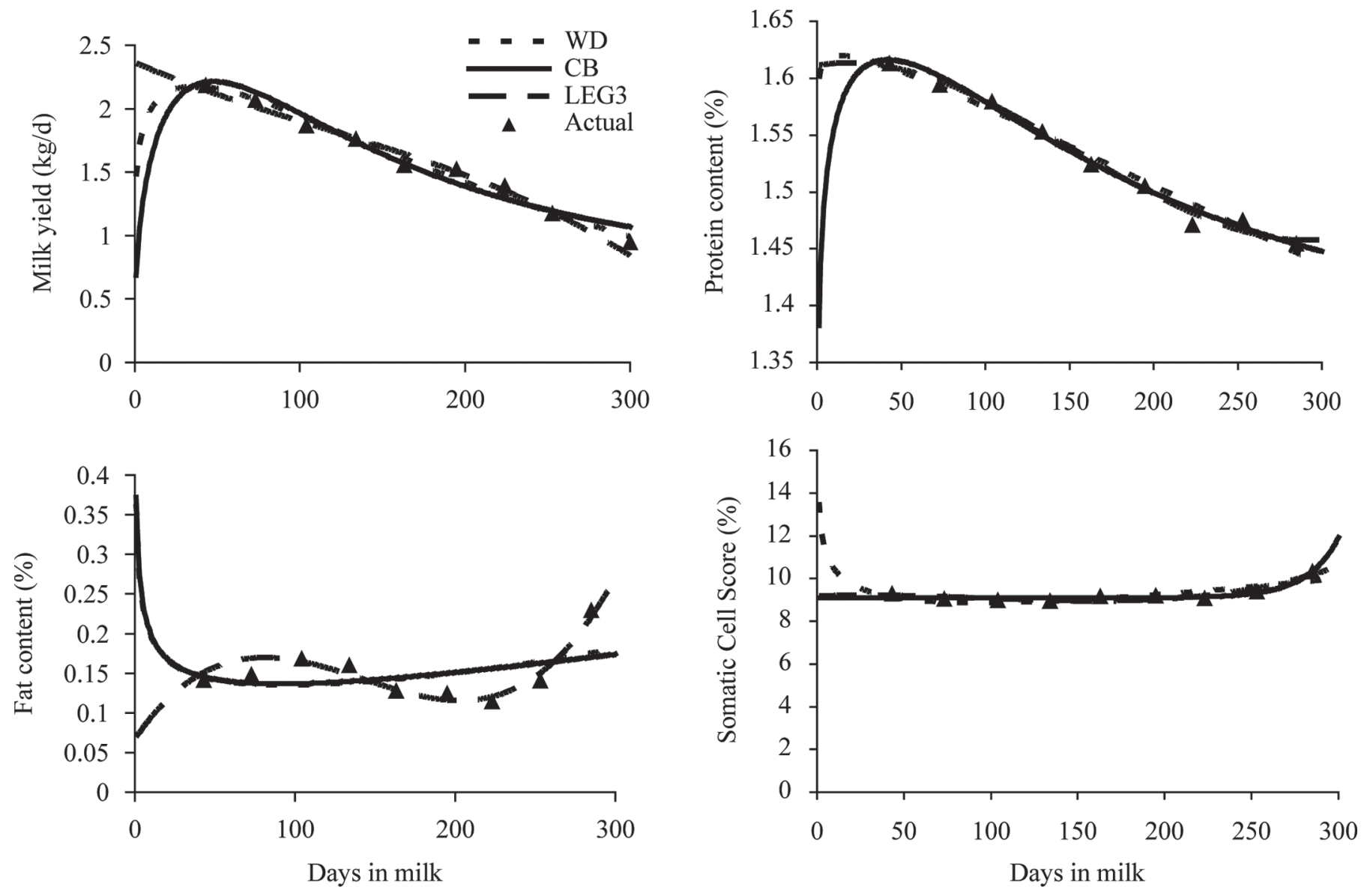

Figure 1. Average lactation curves for (a) milk yield, (b) milk fat content, (c) milk protein content, and (d) SCS estimated by fitting LSM of the DIM factor of model 1 with the Wood (WD), Cappio-Borlino (CB), and Legendre polynomial (LEG3) functions. 


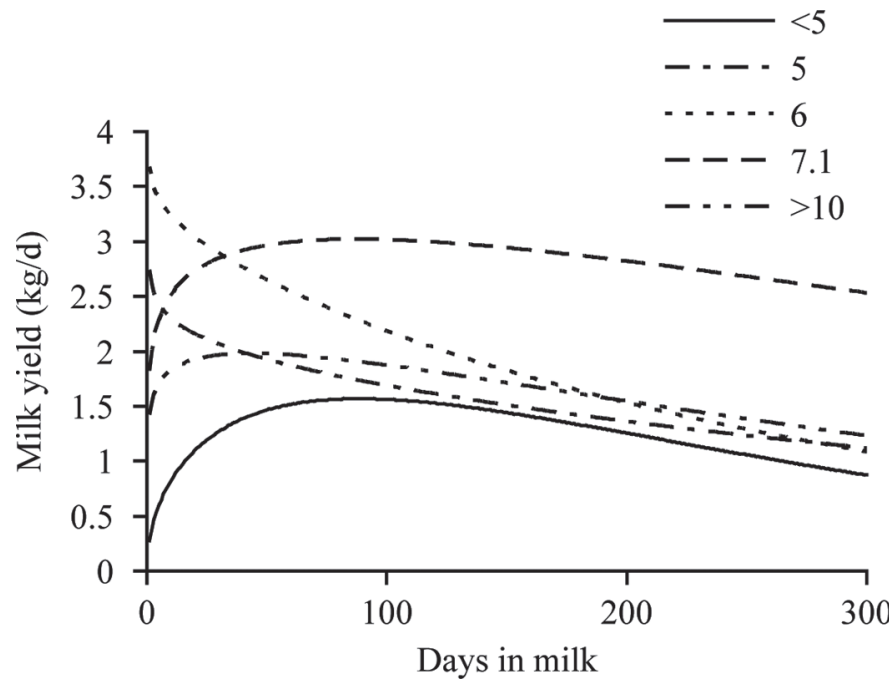

Figure 2. Average lactation curves for milk yield of different age classes obtained by fitting the Wood model to LSM of the DIM factor nested within age class estimated with model 1 .

Protein percentage exhibited a shape similar to the standard for milk yield (Figure 1c). All the functions used were able to detect the occurrence of a peak, located between 9 and 19 DIM (Table 3). A continuously decreasing pattern of milk protein content was reported by Salimei et al. (2004) for Martina Franca and Ragusano breed donkeys. Estimated peak yield values were very close in the 3 models. Similar results were obtained for $\mathrm{R}^{2}$. Results of the DW test highlight a positive autocorrelation between residuals for WD and negative for CB and, especially, LEG3.

Finally, the pattern for SCS was rather flat with a slight tendency to increase in late lactation (Figure 1d). Points of minimum were detected only by WD and LEG3, but the time at their occurrence was markedly different between the 2 models (Table 3 ). For this trait, the CB model yielded the best goodness of fit both in terms of $\mathrm{R}^{2}$ value and of DW statistics.

Lactation curve shapes differed across levels of fixed factors. As an example, fits of the WD model for milk yield are reported in Table 4 and Figures 2, 3, and 4. Standard shapes were obtained for 3 out of 5 age classes, whereas 2 exhibited an atypical pattern (Table 4 and Figure 2). Curves of jennies foaling at less than 5 -yr-old were characterized by a later peak occurrence, lower peak yield, and higher persistency compared with older animals. These features of the curve of the youngest animals are in agreement with previous findings on dairy ruminant species (Cole and Null, 2009; Macciotta et al., 2011). The highest level of production was observed for jennies foaling between 7 and 10 yr of age (Figure 2). Better fitting performances were obtained for older $\left(\mathrm{R}^{2}>0.90\right)$ compared with younger

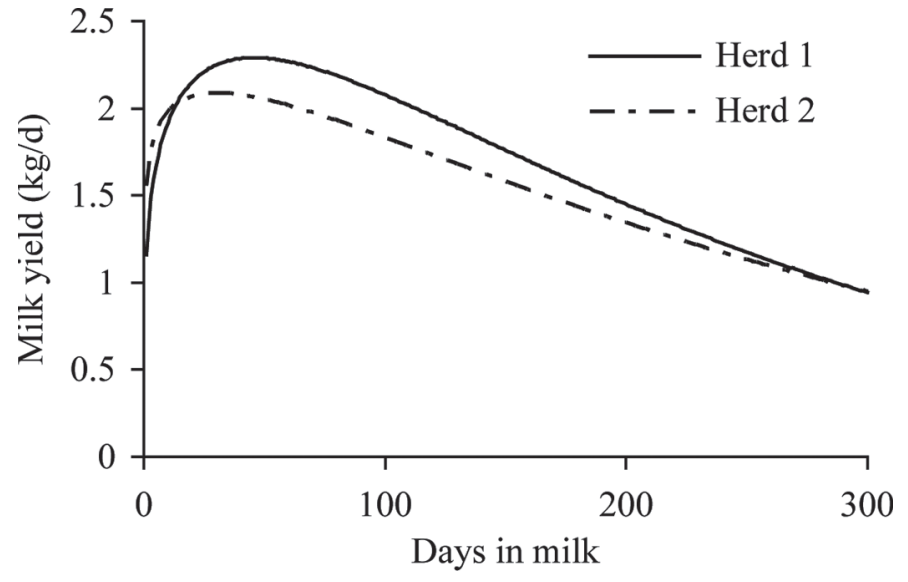

Figure 3. Average lactation curves for milk yield of the 2 herds obtained by fitting the Wood function to LSM of the DIM factor nested within herd estimated with model 1.

$\left(\mathrm{R}^{2}<0.80\right)$ animals, also in terms of autocorrelation between residuals.

Both herds showed a standard lactation curve shape (Figure 3). The difference in production level was more evident around the lactation peak, and it could be detected until 200 DIM. The most productive herd showed a delay in lactation peak occurrence of about $2 \mathrm{wk}$ and a larger value of lactation persistency (Table 4). Finally, lactation curves of different foaling seasons were characterized by differences in average level of production. The curve of jennies foaling in winter was constantly higher than that of spring and, especially,

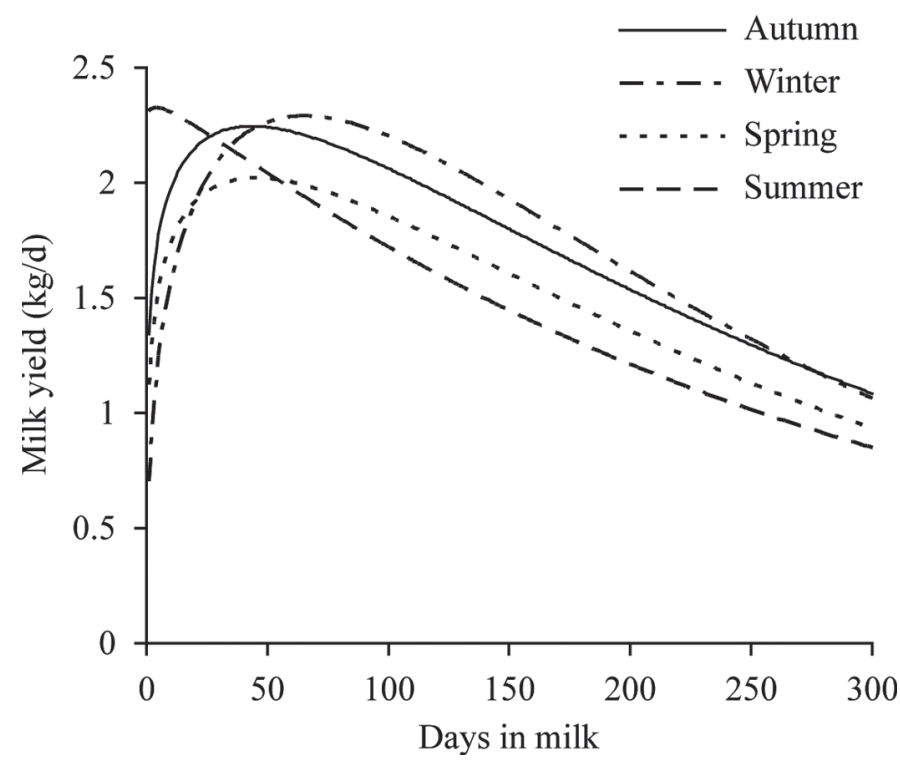

Figure 4. Average lactation curves for milk yield of the different foaling seasons obtained by fitting the Wood function to LSM of the DIM factor nested within foaling season estimated with model 1. 
Table 5. Relative frequencies of individual curve shapes detected by the Wood model for the different traits

\begin{tabular}{lcccc}
\hline Item & $\begin{array}{c}\text { Milk } \\
\text { yield }\end{array}$ & $\begin{array}{c}\text { Fat } \\
\text { content }\end{array}$ & $\begin{array}{l}\text { Protein } \\
\text { content }\end{array}$ & SCS \\
\hline Increasing to a maximum then decreasing & 0.59 & 0.24 & 0.47 & 0.37 \\
Continuously decreasing & 0.19 & 0.14 & 0.16 & - \\
Decreasing to a minimum then increasing & 0.22 & 0.55 & 0.37 & 0.56 \\
Continuously increasing & - & 0.7 & - & 0.7 \\
\hline
\end{tabular}

summer (Figure 4). Another interesting difference can be observed in the peak occurrence (Figure 4), with a marked tendency to delay (about 2 mo) moving from summer to winter.

\section{Individual Lactation Curve Modeling}

A common issue when modeling individual lactation curves for milk yield is represented by the occurrence of atypical patterns (i.e., continuously decreasing). In the present study, the WD model was able to detect about $60 \%$ of standard and $20 \%$ of atypical shapes, respectively (Table 5). The amount of atypical patterns was comparable to values reported for other dairy species (Cappio-Borlino et al., 1997; Macciotta et al., 2005). The occurrence of the third type of shape, similar to fat percentage, was rather unexpected. Actually, a relevant variability of individual lactation shapes was reported for Martina Franca jennies (D'Alessandro and Martemucci, 2012). The median values for peak occurrence and peak yield were $59 \mathrm{~d}$ and $2.01 \mathrm{~kg}$, respectively.

The distribution of individual curve fits among $R^{2}$ classes (Table 5) highlighted some differences between traits and models. In general, milk yield and protein percentage were characterized by a better goodness of fit (more than $60 \%$ of curves having and $\mathrm{R}^{2}>0.6$, except for LEG3 in the case of protein percentage) in comparison with fat content and SCS. As far as the comparison between models is concerned, WD and CB gave basically the same results. The best goodness of fit was obtained for LEG3 of MY, FP, and, to a lesser extent, SCS. This result was quite expected due to the greatest flexibility of this function, which has not been specifically conceived to fit the standard shape of the lactation curve. Completely different results were obtained for protein percentages, with better performances of WD and CB compared with LEG3 (Table 6).

\section{General Discussion}

Some general characteristics of the lactation curve of the donkey have been observed in the present work. The general pattern of milk traits along the lactation basically agrees with those of the most popular dairy species shape, with an exception for protein content. Also, a relevant variability of milk fat content has been observed. It is worth mentioning that the asses considered in the present work were still nursing their foals. Factors affecting milk traits are similar to those in dairy species, for example, the effect of age on average milk yield or lactation curve shape. A large variability of individual lactation curve shape has also been highlighted for donkeys.

As far as the comparison between lactation curve functions is concerned, no differences in goodness of fit have been observed in the case of average curves except for fat percentage, which was poorly fitted by the 2 parametric models. In any case, this is further confirmation of the usefulness of models with a limited number of parameters specifically conceived to fit lactation curve shape when the main interest in the research lies in the reconstruction of the lactation pattern. Conversely, the advantage of using more flexible models is evident when dealing with a large variability of shapes, as in the case of fat percentage or individual patterns for milk yield.

\section{CONCLUSIONS}

Data used in the present work were generated in a dairy recording program for donkey farms that are no longer active. This is an issue that needs to be addressed, because the availability of a database is of great importance for the improvement of performances of a dairy species. At present, about 6,600 donkeys are registered in the national herd book. They could represent an interesting starting point to collect information both for planning coherent management strategies and starting the estimation of genetic parameters for dairy traits in this species.

\section{ACKNOWLEDGMENTS}

This work was partly funded by Istituto Sperimentale Zootecnico per la Sicilia (Palermo, Sicily, Italy). The authors are also grateful to C. Torrisi (Azienda ASILAT, Giarre, Catania, Italy) and R. Leggio (Azienda Tumino, Ragusa, Italy) for their kind collaboration. 


\section{REFERENCES}

Alabiso, M., C. Giosuè, M. L. Alicata, F. Mazza, and G. Iannolino. 2009. The effects of different milking intervals and milking times per day in jennet milk production. Animal 3:543-547.

Ali, A. K. A., and G. Shook. 1980. An optimum transformation for somatic cell concentration in milk. J. Dairy Sci. 63:487-490.

Associazione Italiana Allevatori (AIA). 2012. Equidi per regione. Accessed Sep. 4, 2012. http://www.anagrafeequidi.it/index. php?id $=217$.

Bertino, E., D. Gastaldi, G. Monti, C. Baro, D. Fortunato, L. Perono Garoffo, A. Coscia, C. Fabris, M. Mussap, and A. Conti. 2010. Detailed proteomic analysis on DM: Insight into its hypoallergenicity. Front. Biosci. (Elite Ed) 2:526-536.

Bordonaro, S., A. M. Guastella, A. Criscione, A. Zuccaro, and D. Marletta. 2012. Genetic diversity and variability in endangered pantesco and two other Sicilian donkey breeds assessed by microsatellite markers. Sci. World J. 2012:1-6. http://dx.doi. org $/ 10.1100 / 2012 / 648427$.

Cappio-Borlino, A., N. P. P. Macciotta, and G. Pulina. 1997. The shape of Sarda ewe lactation curve analysed by a compartmental model. Livest. Prod. Sci. 51:89-96.

Cappio-Borlino, A., G. Pulina, and G. Rossi. 1995. A non-linear modification of Wood's equation fitted to lactation curves of Sardinian dairy ewes. Small Rumin. Res. 18:75-79.

Carroccio, A., F. Cavataio, G. D. Montaldo, D. Amico, L. Alabrese, and G. Iacono. 2000. Intolerance to hydrolyzed cow's milk protein in infants: Clinical characteristics and dietary treatment. Clin. Exp. Allergy 30:1597-1603.

Cole, J. B., and D. J. Null. 2009. Genetic evaluation of lactation persistency for five breeds of dairy cattle. J. Dairy Sci. 92:2248-2258.

Colli, L., G. Perrotta, R. Negrini, L. Bomba, D. Bigi, P. Zambonelli, A. Verini Supplizi, L. Liotta, and P. Ajmone-Marsan. 2013. Detecting population structure and recent demographic history in endangered livestock breeds: The case of the Italian autochthonous donkeys. Anim. Genet. 44:69-78

Cosentino, C., R. Paolino, P. Freschi, and A. M. Calluso. 2012. Jenny milk production and qualitative characteristics. J. Dairy Sci. 95:2910-2915.

D'Alessandro, A. G., and G. Martemucci. 2012. Lactation curve and effects of milking regimen on milk yield and quality, and udder health in Martina Franca jennies (Equus asinus). J. Anim. Sci. 90:669-681.

Dijkstra, J., S. Lopez, A. Bannink, M. S. Dhanoa, E. Kebreab, N. E. Odongo, M. H. Fathi Nasri, U. K. Behera, D. Hernandez-Ferrer, and J. France. 2010. Evaluation of a mechanistic lactation model using cow, goat and sheep data. J. Agric. Sci. 148:249-262.

Druet, T., F. Jaffrezic, D. Boichard, and V. Ducroq. 2003. Modeling lactation curves and estimation of genetic parameters for first lactation test-day records of French Holstein cows. J. Dairy Sci. $86: 2480-2490$.

FAO STAT. 2012. Food and Agriculture Organization of the United Nations. Accessed Sep. 4, 2012. http://faostat.fao.org/site/569/ default.aspx \#ancor.

France, J., and J. H. M. Thornley. 1984. Mathematical models in agriculture. Butterworths, London, UK.

Franci, O., C. Pugliese, A. Acciaioli, G. Parisi, and M. Lucifero. 1999. Application of two models to the lactation curve of Massese ewes. Small Rumin. Res. 31:91-96.

Gastaldi, D., E. Bertino, G. Monti, C. Baro, C. Fabris, A. Lezo, C. Medana, C. Baiocchi, M. Mussap, F. Galvano, and A. Conti. 2010. Donkey's milk detailed lipid composition. Front. Biosci. (Elite Ed) $2: 537-546$.

Giosuè, C., M. Alabiso, G. Russo, M. L. Alicata, and C. Torrisi. 2008. Jennet milk production during the lactation in a Sicilian farming system. Animal 2:1491-1495.

Guo, H. Y., K. Pang, X. Y. Zhang, L. Zhao, S. W. Chen, M. L. Dong, and F. Z. Ren. 2007. Composition, physiochemical properties, nitrogen fraction distribution, and amino acid profile of donkey milk. J. Dairy Sci. 90:1635-1643. 
Jamrozik, J., and L. R. Schaeffer. 1997. Estimates of genetic parameters for a test day model with random regressions for yield traits of first lactation Holsteins. J. Dairy Sci. 80:762-770.

Landete-Castillejos, T., and L. Gallego. 2000. Technical note: The ability of mathematical models to describe the shape of lactation curves. J. Anim. Sci. 78:3010-3013.

Littell, R. C., P. R. Henry, and C. B. Hammerman. 1998. Statistical analysis of repeated measures data using SAS procedures. J. Anim. Sci. 76:1216-1231.

Macciotta, N. P. P., C. Dimauro, S. P. G. Rassu, R. Steri, and G. Pulina. 2011. The mathematical description of lactation curves in dairy cattle. Ital. J. Anim. Sci. 11:213-223.

Macciotta, N. P. P., C. Dimauro, R. Steri, and A. Cappio-Borlino 2008. Mathematical modelling of goat lactation curves. Pages 31-46 in Dairy Goats Feeding and Nutrition. A. Cannas and G. Pulina, ed. CAB International, Wallingford, UK.

Macciotta, N. P. P., D. Vicario, and A. Cappio-Borlino. 2005. Detection of different shapes of lactation curve for milk yield in dairy cattle by empirical mathematical models. J. Dairy Sci. 88:11781191.

Monti, G., E. Bertino, M. C. Muratore, A. Coscia, F. Cresi, L. Silvestro, C. Fabris, D. Fortunato, M. G. Giuffrida, and A. Conti. 2007. Efficacy of donkey's milk in treating highly problematic cow's milk allergic children: An in vivo and in vitro study. Pediatr. Allergy Immunol. 18:258-264.

Salimei, E., and F. Fantuz. 2012. Equid milk for human consumption. Int. Dairy J. 24:130-142.
Salimei, E., F. Fantuz, R. Coppola, B. Chiofalo, P. Polidori, and G. Varisco. 2004. Composition and characteristics of ass's milk. Anim. Res. 53:67-78.

Santos, A. S., and A. M. Silvestre. 2008. A study of Lusitano mare lactation curve with Wood's model. J. Dairy Sci. 91:760-766.

SAS Institute. 2008. User's Guide: Statistics. Version 9.2. SAS Institute Inc., Cary, NC.

Schaeffer, L. R. 2004. Application of random regression models in animal breeding. Livest. Prod. Sci. 86:35-45.

Silvestre, A. M., A. M. Martins, V. A. Santos, M. M. Ginja, and J. A. Colaço. 2009. Lactation curves for milk, fat and protein in dairy cows: A full approach. Livest. Sci. 122:308-313.

Stanton, T. L., L. R. Jones, R. W. Everett, and S. D. Kachman. 1992 Estimating milk, fat, and protein lactation curves with a test day model. J. Dairy Sci. 75:1691-1700.

Strucken, E. M., D. J. de Koning, S. A. Rahmatalla, and G. A. Brockmann. 2011. Lactation curve models for estimating gene effects over a timeline. J. Dairy Sci. 94:442-449.

Tesse, R., C. Paglialunga, S. Braccio, and L. Armenio. 2009. Adequacy and tolerance to ass's milk in an Italian cohort of children with cow's milk allergy. Ital. J. Pediatr. 35:19.

Tidona, F., C. Sekse, A. Criscione, M. Jacobsen, S. Bordonaro, D. Marletta, and G. E. Vegarud. 2011. Antimicrobial effect of donkeys' milk digested in vitro with human gastrointestinal enzymes. Int. Dairy J. 21:158-165.

Wood, P. D. P. 1967. Algebraic model of the lactation curve in cattle. Nature 216:164-165. 